\title{
Erratum zu: Systematische Potentiale der philosophischen Anthropologie
}

Amir Mohseni / Michael Quante

\section{Erratum zu:}

Kapitel ,Systematische Potentiale der philosophischen Anthropologie" in: G. Hartung und M. Herrgen (Hrsg.), Interdisziplinäre Anthropologie, Interdisziplinäre Anthropologie, https://doi.org/10.1007/978-3-658-14264-3_17

Der korrekte Name des Autors zum Beitrag ,Systematische Potentiale der philosophischen Anthropologie“, in diesem Band auf den Seiten VII und 243ff. genannt, lautet wie folgt: Amir Mohseni

Die korrigierte Version des Kapitels ist verfügbar unter

https://doi.org/10.1007/978-3-658-14264-3_17 